\title{
Efficacy of Prophylactic Phototherapy for Prevention of Hyperbilirubinemia in Very Low Birth Weight Newborns
}

\author{
M A Mannan', Ismat Jahan², Sadeka Choudhury Moni ${ }^{2}$, Zahidul Hasan², Arjun Chandra Dey ${ }^{3}$, Mohammod \\ Shahidullah ${ }^{1}$ \\ ${ }^{1}$ Professor, ${ }^{2}$ Resident, ${ }^{3}$ Assistant Professor, Department of Neonatology, Bangabandhu Sheikh Mujib Medical University (BSMMU), Dhaka.
}

\begin{abstract}
:
Background: Jaundice is a common clinical condition in newborn occurring in approximately $60 \%$ of term and $80 \%$ of preterm infants. Unconjugated hyperbilirubinemia is universally common in all preterm infants especially in newborns with very low birth weight. Low birth weight and premature infants are at major risk for exaggerated hyperbilirubinemia that can lead to bilirubin encephalopathy. Significant heterogeneity in the approach to the treatment of jaundiced neonates exists throughout the world. Phototherapy is the most common treatment for neonatal hyperbilirubinemia and could be most effective in preventing the sequelae of hyperbilirubinemia if initiated prophylactically. This randomized clinical trial has been proposed with the objective of assessing the efficacy of prophylactic phototherapy in preventing significant rise of unconjugated hyperbilirubinemia in premature neonates weighing less than 1500 gram and therefore to decrease the need for exchange transfusion and finally to reduce hospital stay due to hyperbilirubinemia. Methods: This randomized controlled clinical trial enrolled sixty newborns with birth weight less than 1500 gram. They were divided into two groups: 1) Prophylactic group, in whom phototherapy was started within 24 hours of birth and continued for 7 days and 2) Control group in whom therapeutic phototherapy was started considering serum bilirubin level and other clinical conditions as per institutional guidelines. Mean value of total serum bilirubin (TSB), duration of phototherapy, the need for exchange transfusion and duration of hospital stay in both groups were analyzed. Results: The maximum mean TSB level in prophylactic group was observed on 7th day and in control group it was observed on 3rd day of life. The total serum bilirubin levels were significantly lower in the $3 \mathrm{rd}$ and 5 th days of life in the prophylactic group in comparison to control group ( $\mathrm{P}$ value 0.001$)$. Total serum bilirubin level exceeded therapeutic range in $6(21 \%)$ and $14(50 \%)$ newborns of the prophylactic group and control groups respectively ( $\mathrm{P}$ value 0.026$)$.No documented side effects of prophylactic phototherapy was observed. Conclusion: The use of prophylactic phototherapy for infants weighing less than $1500 \mathrm{gm}$ is effective and safe when compared to the control group, considering satisfactory maintenance of low total serum bilirubin levels during first 7 days of life.
\end{abstract}

Key words: Phototherapy, Neonatal jaundice, Preterm, Very low birth weight newborn

[BSMMUJ 2013; 6 (2) : 151-155]

\section{Introduction:}

Jaundice is a common clinical condition in newborn occurring in approximately $60 \%$ of term infants and $80 \%$ of preterm infants. Unconjugated hyperbilirubinemia is universally common in all preterm infants especially in newborns with very low birth weight. Studies showed that the large amount of short-lived red blood cells and the increase in enterohepatic circulation of bilirubin and the deficient hepatic conjugation of bilirubin are the most Address for Correspondence: M A Mannan Professor, Department of Neonatology Bangabandhu Sheikh Mujib Medical University (BSMMU), Dhaka. important physiological conditions that cause exacerbation of hyperbilirubinemia. In addition, the delayed implementation of enteral nutrition, which is common in critically ill preterm newborns, may restrict intestinal blood flow and enhance the enterohepatic reuptake of bilirubin ${ }^{1}$. On top of that, patient admitted to intensive care may show association of predisposing factors for penetration of bilirubin into the brain, such as hypoxemia, acidosis, hypothermia, hypoalbuminemia and hypercapnia ${ }^{2}$. Three recognized treatment modalities of jaundice in newborns are phototherapy, exchange transfusion and drugs. Significant heterogeneity in the approach 
to the treatment of jaundiced neonate was documented in an international survey conducted by Hensen ${ }^{3}$. Until $2002^{4}$, the American Academy of Pediatrics considered that there was a paucity of properly designed studies and observational data on low birth weight newborns without hemolytic disease, which hinders the development of a specific treatment routine. But in relation to unconjugated hyperbilirubinemia in preterm newborns, in several studies published in the $1990 \mathrm{~s}^{5,6}$, causal relationship between Hyperbilirubinemia (total serum billirubin $<15$ $\mathrm{mg} / \mathrm{dl}$ ) and neurological, hearing, visual, speech and developmental disorders is not evident.

Nevertheless, in 2001, Sugama et al. ${ }^{7}$ questioned the rare occurrences of bilirubin encephalopathy in preterm newborns after they detected kernicterus in two patients at 31 and 34 weeks of gestational age respectively, with bilirubin levels between 13.1 and $14.7 \mathrm{mg} / \mathrm{dl}$; none of the patients had symptoms that could suggest the disease in the neonatal period. With this background, because of the high frequency, serious sequelae, and hazardous as well as risky and costly management especially where exchange transfusion is indicated, neonatal jaundice is a good candidate for preventive treatment. Phototherapy as well as phenobarbitone has been evaluated as prophylactic agents for neonatal jaundice. Both the modalities are effective in decreasing the peak TSB ${ }^{8,9}$. Several clinical trials have been done worldwide using phenobarbitone to newborns as prophylaxis of non-hemolytic hyperbilirubinemia ${ }^{10-13}$. But requirement of high prophylactic dose $(10-12 \mathrm{mg} / \mathrm{kg})$ and its side effect recommends further research on this regard.

Neonatal phototherapy, a noninvasive, safe and easily available therapy, has been exclusively used for the treatment of neonatal jaundice worldwide for more than half a century ${ }^{14}$. Its efficacy in decreasing plasma bilirubin concentration is well documented, and phototherapy leads to greatly reduced exchange transfusion rates for neonates with hyperbilirubinemia.

Prophylactic phototherapy signifies initiation of phototherapy between 12 and 24 hours of life, regardless of the bilirubin level. Few trials on prophylactic phototherapy have been conducted worldwide. Hansen, in $1996^{3}$, attempted to compare the several types of treatment for neonatal jaundice in several countries. Of 218 questionnaires, 108 were filled out and returned, of which $53(49 \%)$ showed the use of prophylactic phototherapy. Leite \& Facchini ${ }^{15}$ in Brazil assessed early and late initiation of phototherapy. The authors concluded that early treatment is safer that late treatment.

Therefore prevention of kernicterus in preterm infants is still an unsolved problem. There is no level, there probably never was a level, nor there will be a level of bilirubin to exclude the disease $\mathrm{e}^{16}$, so this field constitutes an important field for preventive care. So far we know, no trial has been reported on prophylactic phototherapy anywhere in our country. With this background this study has been designed in a tertiary care hospital to assess the efficacy of prophylactic phototherapy in preventing significant rise of unconjugated bilirubinemia in premature neonate weighing less than 1500 grams and therefore to decrease the need for exchange transfusion and finally to reduce hospital stay due to hyperbilirubinemia.

\section{Methods:}

It was a prospective randomized controlled trial conducted during a period of six months from July 2012 to December 2012 in the Neonatal Intensive Care Unit (NICU) of Bangabandhu Sheik Mujib Medical University (BSMMU). The study population were premature newborn infants weighing $<1500$ gram . The objective of the study was to assess the efficacy of prophylactic phototherapy in preventing significant rise of unconjugated hyperbilirubinemia in premature neonates weighing less than 1500 grams and therefore to decrease the need for therapeutic phototherapy as well as exchange transfusion and finally to reduce hospital stay due to hyperbilirubinemia. Inclusion criteria were preterm newborn infants < 1500 gram who were admitted within 24 hours of birth in NICU during the study period. Exclusion criteria were neonates with severe RDS, perinatal asphyxia, severe sepsis, hemolytic disease of newborn, infants with major congenital abnormalities and babies born to mother receiving phenobarbitone in the antenatal period. The study was approved by the Institutional review board. Informed written consents were obtained from the 
parents.

Enrolled infants were randomly assigned into prophylactic and control group. Phototherapy was started within 24 hours of birth in the prophylactic group and continued up to 7 days. Therapeutic phototherapy was started in control group considering serum bilirubin level and other clinical conditions as per existing institutional guidelines. Phototherapy was administered continuously by standard phototherapy units (ARDO,Amelux) using standard procedures in both the groups. All phototherapy units contained four special blue lamps (Philips, maximum power 36 watt) and were adjusted to be $20 \mathrm{~cm}$ above the infants. Lamps were changed regularly after 1000 hours of utilization. Serum bilirubin was measured at the start of phototherapy and then every alternate day for 7 days. First sample was taken to measure baseline serum bilirubin along with sample for blood group and complete blood count on day 1 . Second sample was taken with routine biochemical tests on day 3 . Other tests were done when clinically indicated. Serum bilirubin level (total and direct) was measured by Bilirubinometer and determination of direct bilirubin was made by the colorimetric method of Lathe and Ruthven. The criteria to omit phototherapy and to initiate exchange transfusion were same for both the groups. All other therapeutic interventions were uninterrupted. Primary outcome variables were maximum bilirubin level and days required for serum bilirubin to come down to a safe level $(2 \mathrm{mg} / \mathrm{dl}$ below the phototherapy range) in both groups. Secondary outcome variables were duration of hospital stay and need for exchange transfusion in both the groups.

Data were collected by standard questionnaire and check list. The obtained data were transferred to coding sheets in a computer database. All analyses were performed using SPSS software 19 version for windows. Descriptive statistics was presented as proportions for categorical variables and mean \pm SD for continuous variables. Numeric variables were compared between the two groups using the independent Student's t test. The Chi-square test was used to compare categorical variables between the two groups. A P-value of less than 0.05 was considered statistically significant.

\section{Results:}

A total of 60 very low birth weight (VLBW) newborn infants of $<1500$ gram were included and randomly assigned to prophylactic or control group. Two babies from each group died due to severe RDS and sepsis. Data were analyzed for 28 babies from prophylactic group and 28 babies from control group.

There were no significant differences between both the groups regarding the mean gestational age, birth weight, occipitofrontal circumference(OFC), length, gender distribution, and mode of delivery (Table-I).

\section{Table-I}

Demographic characteristics of both the groups. $(n=56)$

\begin{tabular}{llll}
\hline $\begin{array}{l}\text { Demographic } \\
\text { data }\end{array}$ & $\begin{array}{l}\text { Prophylactic } \\
\mathrm{n}=28\end{array}$ & $\begin{array}{l}\text { Control } \\
\mathrm{n}=28\end{array}$ & P-value \\
\hline
\end{tabular}

Gestational

age(wks)

Mean \pm SD $\quad 33.04 \pm 1.453 \quad 33.11 \pm 1.4490 .855$

Birth

weight(gm)

Mean \pm SD $\quad 1321.79 \pm 164.081305 .71 \pm 1490.703$

$\mathrm{OFC}(\mathrm{cm})$

Mean \pm SD $\quad 27.48 \pm 1.01 \quad 27.12 \pm 0.7150 .134$

Length $(\mathrm{cm})$

$\begin{array}{llll}\text { Mean } & \text { SD } \quad 39.42 \pm 1.75 & 38.25 \pm 2.15 & 0.293\end{array}$

Sex: Male(\%) $53 \quad 60.7$

$\begin{array}{lll}\text { Female }(\%) & 47 & 39.3\end{array}$

0.296

Mode

delivery:

NVD(\%)

28.6

28.6

0.616

$\operatorname{LSCS}(\%)$

71.4

71.4

Mean serum bilirubin level was significantly lower in the prophylactic group on 3rd and 5th days of life in comparison to control group ( $\mathrm{P}$ value 0.001 ). Also maximum mean total serum bilirubin was low $(5.25 \pm 1.27)$ in prophylactic group and it reached at day 7 while it was $(8.7 \pm 3.9)$ in control group which was observed earlier on day 3 (Table-II). 
Table-II

Total serum bilirubin of prophylactic and control groups

\begin{tabular}{llll}
\hline $\begin{array}{l}\text { Total serum } \\
\text { bilirubin(TSB) } \\
\mathrm{mg} / \mathrm{dl}\end{array}$ & $\begin{array}{l}\text { Prophylactic } \\
\mathrm{n}=28 \\
\text { Mean } \pm \mathrm{SD}\end{array}$ & $\begin{array}{l}\text { Control } \\
\mathrm{n}=28\end{array}$ & Pean $\pm \mathrm{SD}$ \\
\hline 1st Day & $2.5(0.89)$ & $2.58(0.60)$ & 0.945 \\
3rd Day & $3.9(1.66)$ & $8.7(3.9)$ & 0.001 \\
5th Day & $4.8(1.37)$ & $7.7(2.9)$ & 0.001 \\
7th Day & $5.25(1.27)$ & $4.7(1.8)$ & 0.272 \\
\hline
\end{tabular}

Table III showing total serum bilirubin level exceeded therapeutic range in $6(21 \%)$ and $14(50 \%)$ newborns of the prophylactic group and control groups respectively ( $\mathrm{P}$ value 0.026 ). No difference was found in respect to duration of hospital stay in both the groups.

\section{Table-III}

TSB exceeded therapeutic range and hospital stay in both groups

\begin{tabular}{lll}
\hline Prophylactic & Control & P-value \\
$\mathrm{n}=28$ & $\mathrm{n}=28$ & \\
$\mathrm{no} \%$ & $\mathrm{no} \%$ & \\
\hline
\end{tabular}

TSB exceeded

therapeutic range $6(21 \%) \quad 14(50 \%) \quad 0.026$

(\%)

Duration of

hospital stay $\quad 33.64 \pm 11.02935 .68 \pm 13.1150 .532$

(days)

Mean \pm SD

Prophylactic phototherapy was started earlier and was continuing for longer duration in prophylactic group in comparison to control group ( $\mathrm{P}$ value 0.001 ). One neonate in the control group required exchange transfusion due to sepsis. There was no major side effects of phototherapy was observed and all were discharged in good health.

\section{Discussions:}

In this study, the mean serum bilirubin was significantly lower in prophylactic group compared with that in control group on $3^{\text {rd }}$ and $5^{\text {th }}$ day of life. Total serum bilirubin level exceeded therapeutic range in $6(21 \%)$ and $14(50 \%)$ newborns of the prophylactic group and control group respectively ( $\mathrm{P}$ value 0.026 ).

Another controlled randomized clinical trial by Leite \& Facchini ${ }^{15}$ assessed early and late initiation of phototherapy in newborns weighing less than 2000 gram without hemolytic disease. The authors measured the concentration of transcutaneous bilirubin on a daily basis and concluded that early treatment, implemented at 12 hours of life, is safer that late treatment because it maintains bilirubin levels below $10 \mathrm{mg} / \mathrm{dl}$. In this study, mean duration of phototherapy was also longer in prophylactic group ( $160 \pm 7.104$ vs $95 \pm 33.25)$ which shows similarity with the finding demonstrated by Leite \& Facchini15. Early initiation of phototherapy and late rise of maximum total serum bilirubin might explain this finding.

Tripathi et al. ${ }^{17}$ conducted a prospective unblinded study where 50 newborns were randomly assigned to control and prophylactic phototherapy groups. According to their study, phototherapy was started significantly earlier $(4.18 \pm 3.64$ in prophylactic group compared with $46.80 \pm 6.44$ in control group, $\mathrm{P}$ value was $<0.001$ ) and was continuing for longer duration in hours $(164 \pm 36$ and $83 \pm 44$ in prophylactic and control groups respectively, $\mathrm{P}$ value 0.009 ).Though they started prophylactic phototherapy earlier and given for a longer period, they could not find significant difference in the age of reaching peak bilirubin levels in either group. In this study, initiation and continuation of prophylactic therapy were similar but significant difference in mean serum bilirubin was observed in 3rd and 5th day of life which contradicts with the findings of the study done by Tripathi et al.

Ramin et al. ${ }^{18}$ conducted a similar type of study in Iran with the aim to compare two phototherapy methods (prophylactic vs therapeutic) for the management of hyperbilirubinemia in very low birth weight newborns weighing 1000-1500 gram. Sixty newborns were divided into prophylactic group in which phototherapy was started within 6 hours of age and continued for at least 96 hours and treatment group, which received phototherapy when indicated. In the prophylactic group, the highest daily mean TCB was $7.71 \pm 1.84 \mathrm{mg} / \mathrm{dl}$, which happened on the third day. In the treatment group, it was $8.74 \pm 1.72 \mathrm{mg} / \mathrm{dl}$ on the fourth day of life. The TCB values in prophylactic 
group and control group were observed on $7^{\text {th }}$ and $3^{\text {rd }}$ day of life respectively. Our study also showed similar findings that the total serum bilirubin levels were significantly lower in prophylactic group when compared to control group on the $3^{\text {rd }}$ and $5^{\text {th }}$ day of life. According to Ramin et al $^{18}$, total bilirubin level exceeded $8 \mathrm{mg} / \mathrm{dl}$ in 29 $(96.6 \%)$ and $18(60 \%)$ newborns of treatment and prophylactic group respectively $(\mathrm{P}=0.01)$. This study also found similar findings that control group exceeded TSB that required therapeutic phototherapy than prophylactic group.

\section{Conclusion:}

Prophylactic phototherapy is effective and safe in maintaining lower serum bilirubin level within first week of life and it decreased the chance for the development of significant hyperbilirubinemia. However it does not affect the need of exchange transfusion and the duration of hospital stay in premature very low birth weight babies.

\section{References:}

1. Cashore WJ. Bilirubin and jaundice in the micropremie. Clin Perinatol. 2000; 27:171-9.

2. Watchko JF, Maisels MJ. Jaundice in low birthweight infants pathobiology and outcome. Arch Dis Child Fetal Neonatal. 2003;88:455-62

3. Hansen TWR. Therapeutic approaches to neonatal jaundice: an international survey. Clin Pediatr. 1996; 35:309-16.

4. American Academy of Pediatrics and American College of Obstetricians and Gynecologists. Guidelines for perinatal care. 5th ed. Elk Grove Village: American Academy of Pediatrics; 2002.

5. Scheidt PC, Bryla DA, Nelson KB, Hoffman HJ. Phototherapy for neonatal hyperbilirubinemia: six-year follow-up of the National Institute of Child and Human Development clinical trial. Pediatrics. $1990 ; 85: 455-62$.
6. Van de Bor M, Ens-Dokkum M, Schreuder AM, Veen S, Brand $\mathrm{R}$, Verloove-Vanhorick SP. Hyperbilirubinemia in low birth weight infants and outcome at 5 years of age. Pediatrics. 1992; 89:359-64.

7. Sugama S, Soeda A, ETO Y. Magnetic Resonance Imaging in three children with kernicterus. Pediatr Neurol. 2001; 25:328-31.

8. Meloni T, Cagnazzo G, Dose A, Cutillo O. Phenobarbital for prevention of hyperbilirubi-nemia in glucose-6-phosphate dehydrogenase-deficient newborn infants. J Pediatr 1973; 79: 1078-1081.

9. Valdes as, Maurer HM, Shumway CN, Draper AD, Hossaini AA. Controlled clinical trial of phenobarbital and or light in reducing neonatal hyperbilirubinemia in a predominantly Negro population. J Pediatr 1973; 79: 1015-1017.

10. Trolle, D. (1968a). Phenobarbitone and neonatal icterus. ibid.,1, 251 .

11. Trolle, D. (1968b). Decrease of total serum-bilirubin concentration in newborn infants after phenobarbitone treatment. ibid., 2, 705.

12. Maurer, H. M., Wolff, J. A., Finster, M., Poppers, P. J., Pantuck, E., Kuntzmann, R., and Conney, A. H. (1968). Reduction in concentration of total serum-bilirubin in offspring of womentreated with phenobarbitone during pregnancy. ibid., 2, 122.

13. Rajesh Kumar, Anil Narang, Praveen Kumar and Gurjeevan Garewal .Phenobarbitone Prophylaxis for Neonatal Jaundice in Babies with birth Weight 1000-1499 Grams. Indian Pediatrics 2002; $39 ; 945-951$

14. Xiong T, Qu Y, Cambier S, Mu D. The side effects of phototherapy for neonatal jaundice: what do we know? What should we do? Eur J Pediatr. 2011 Apr 1.

15. Leite MGC, Facchini FP. Avaliação de dois esquemas de indicação de fototerapia em recém-nascidos com peso menor que $2.000 \mathrm{~g}$. J Pediatr (Rio J). 2004; 80:285-90.

16. Lucey JF. Bilirubin and brain damage: a real mess. Pediatrics.1982; 69:381-2.

17. Tripathi S, Saili A. Effect of prophylactic phototherapy on neonatal hyperbilirubinemia of prematures. Indian J Med Sci 2006; 60(9):385-7.

18. Ramin I, Majid M, Seyedeh S. Comparison of two phototherapy methods (prophylactic vs therapeutic) for the management of hyperbilirubinemia in very low birth weight newborns. Iran J Pediatr Dec 2011; 21(4), 425-430. 